\title{
The disability system and programs to promote employment for people with disabilities
}

\author{
David Wittenburg ${ }^{1 *}$, David R Mann ${ }^{1}$ and Allison Thompkins ${ }^{2}$
}

\author{
* Correspondence: dwittenburg@ \\ mathematica-mpr.com \\ ${ }^{1}$ Mathematica Policy Research, P.O. \\ Box 2393, Princeton, NJ 08543-2393, \\ USA \\ Full list of author information is \\ available at the end of the article
}

\begin{abstract}
This paper examines employment-focused interventions within the US disability system. Our review illustrates the challenges of developing and implementing these types of initiatives, despite substantial policy interest. Our findings indicate that none of the demonstrations we reviewed have the potential to lead to substantial caseload reductions that could reverse program growth. However, they can inform future designs, particularly the importance of customizing supports to very well-defined target populations.

JEL code: D04

Keywords: Disability, Demonstration, Evaluation, Random assignment
\end{abstract}

\section{Introduction}

Over the past 30 years, there have been a growing number of interventions designed to promote employment among people with disabilities, particularly those receiving public cash benefits and other supports. In part, this interest reflects a desire by policymakers to stem the large caseload increases in programs that provide cash supports to people with disabilities, such as Social Security Disability Insurance (SSDI) and Supplemental Security Income (SSI). However, it also reflects a broader policy objective to integrate people with disabilities into all aspects of society.

Identifying approaches that can produce substantial reductions in caseload growth has been a difficult task. Employment interventions must help people with disabilities overcome substantial employment barriers-such as loss of human capital resulting from disability and prolonged separation from the workforce-and disincentives, including the loss of disability benefits at only modest earnings levels. For instance, eligibility criteria for SSDI and SSI require that applicants demonstrate an inability to work above a certain earnings threshold before applying for benefits, and once on benefits, ongoing eligibility is contingent on maintaining very low earnings levels as well as continuing to have a disabling medical condition. In addition to the challenges experienced by beneficiaries, the structure of the United States' disability system acts as a potential barrier to reform. Several different types of supports exist for people with disabilities, but the supports are administered by different federal, state, and, in some cases, local entities. The implication is that most employment initiatives modify the parameters of one agency's disability support program rather than modifying supports across multiple programs or assisting people with disabilities before they request cash or other types of supports, such as health insurance. 
This paper summarizes the available evidence from rigorous, large-scale evaluations of employment-focused interventions targeting people with disabilities. We focus on interventions where there is a rigorous evaluation design and estimated impacts on employment outcomes. We include several demonstrations funded by the Social Security Administration (SSA) as well as other federal agencies, including the Centers for Medicare \& Medicaid Services (CMS) and Substance Abuse and Mental Health Services Administration (SAMHSA). In reviewing these initiatives, we summarize the key evaluation findings and identify lessons for designing interventions for people with disabilities.

Our findings indicate that none of the demonstrations we reviewed have the potential to lead to substantial caseload reductions that could reverse program growth. We do find, however, that some intensive interventions targeted at specific populations showed positive employment impacts. The interventions that demonstrated the most promising effects tended to provide customized supports to more narrowly targeted subgroups, particularly younger persons and those with psychiatric impairments. Our findings also highlight the challenges that federal agencies face in developing broad employment initiatives, which have likely limited the interventions' effects. There are substantive lessons to be learned from all demonstrations-including those that failed to have large impacts on employment. In particular, a number of demonstrations have shown the importance of starting with smaller pilots before full-scale implementation of a larger policy initiative.

We begin this paper by providing contextual information about the challenges in developing employment initiatives within the existing system of publicly provided disability supports. We then describe the findings from rigorous evaluations of employment interventions that have been tested over the past several decades and some ongoing innovative demonstration projects that are currently in the field. We conclude with a summary and discuss what lessons the existing evidence base offers.

\section{Challenges to developing employment initiatives}

The United States has a complex network of public disability support programs that provide cash, health care, rehabilitation, and employment supports to people with disabilities. These programs were created at different points in history-most at least 35 years agoand have various state and federal agencies that oversee their administration. As a result, there is no single agency that provides a universal set of supports to people with disabilities. Rather, multiple programs exist, each with its own administrative structure, funding stream, and eligibility requirements. As we describe below in greater detail, the program eligibility rules and fragmented support system create barriers for program participants seeking employment as well as for agencies wanting to develop initiatives that address the multiple employment barriers faced by those with disabilities.

\section{Disability supports emphasize income maintenance and health supports}

Stapleton and Livermore (2011) document that in 2008, federal and selected state program spending for working-age people with disabilities totaled $\$ 429$ billion dollars, with over 95 percent of these expenditures devoted to income support and health care. The primary programs providing these benefits are SSDI, SSI, Medicare, and Medicaid. The SSI and SSDI programs, both administered by SSA, are the two largest cash transfer 
programs targeted to people with disabilities. The SSDI program is a social insurance program designed to replace a portion of lost income for workers with disabilities and their dependents. The SSI program is an income-maintenance program for low-income adults and children who meet certain income and asset criteria. Both programs have experienced substantial caseload growth in recent years. From 1980 to 2010, the number of SSDI beneficiaries more than doubled and the number of SSI recipients tripled (Social Security Advisory Board 2012). In 2011, there were 11.7 million SSDI beneficiaries and 9.3 million disabled SSI beneficiaries (Social Security Administration 2012).

Most SSDI and SSI beneficiaries qualify for Medicare and Medicaid, respectively. Although there are eligibility and health coverage differences between Medicare and Medicaid, both offset potentially expensive medical care costs and therefore may be more valuable to people with disabilities than the SSDI and SSI cash benefits. SSI beneficiaries (in most states) are categorically eligible for Medicaid, and SSDI beneficiaries become eligible for Medicare after a two-year waiting period following SSDI eligibility. ${ }^{1}$ As will be discussed in more detail below, the combined value of the cash and health supports are large, and the fear of losing those supports through excess earnings might substantially limit interest in employment activities among SSDI and SSI beneficiaries.

Employment and rehabilitation supports are not as well funded as income and health care supports. Stapleton and Livermore (2011) estimate that just over 1 percent of all federal and state outlays in 2008 were for employment supports for working-age people with disabilities. State Vocational Rehabilitation (VR) programs provide the largest source of support for rehabilitation and employment services. The target population for VR services generally includes any individual who has a work limitation and who can benefit from VR services to achieve an employment outcome. VR's ability to provide services to all eligible people with disabilities is often limited by funding availability; however, service priority is given to people with the most significant disabilities, such as those who receive SSDI and SSI benefits. ${ }^{2}$

\section{SSA Disability program participants face many barriers to returning to work}

A major challenge in developing effective employment interventions for people with disabilities is SSA's requirement that disability support applicants and beneficiaries have conditions that prohibit their ability to make meaningful contributions to their own support through work. Specifically, SSDI and SSI initial and ongoing eligibility criteria require that eligible applicants have a medically determinable disability expected to last at least 12 months or result in death and be unable to engage in substantial gainful activity (SGA). In 2013, SGA is defined as the ability to earn at least $\$ 1,010$ per month in unsubsidized employment for non-blind beneficiaries ( $\$ 1,690$ for blind beneficiaries).

The process of establishing eligibility has important implications for future employment efforts given that the process to establish eligibility for SSDI and SSI is lengthy. During this time period, applicants may be out of the workforce for several months to several years. For example, according to the Social Security Advisory Board (2012), initial disability determinations take an average of 120 days. However, most initial determinations are rejected, and substantial portions of these determinations are appealed, which can further lengthen the application process for benefits for up to several years. Some have noted that the rules for ongoing disability income support eligibility create a 
"poverty trap," whereby people continue to receive benefits with little hope of returning to work (Stapleton et al. 2006). Specifically, Stapleton et al. (2006) note that beneficiaries often feel dependent on these programs and fearful of engaging in work activity, while program administrators and the rehabilitation providers who provide employment supports to these populations often view beneficiaries as incapable of working at substantial levels. Although both SSDI and SSI include modest employment incentives that allow beneficiaries to retain some earnings, the amount is not enough to help beneficiaries rise out of poverty. For the large number of SSA disability beneficiaries who are automatically eligible for and enrolled in other income-based support services such as food and housing assistance, the decision to work could also jeopardize their eligibility for other important benefits.

\section{Challenges to designing employment interventions}

The United States Government Accountability Office (GAO) (2005a) found substantial fragmentation of supports across multiple programs and agencies, which created major inefficiencies in service delivery and perverse incentives in promoting outcomes such as employment. Over 21 federal agencies and about 190 programs provide assistance to people with disabilities, including cash, health, rehabilitation, employment, and other supports. Approximately half of these programs are dedicated specifically to serving people with disabilities, whereas the remaining programs are available to those with and without disabilities. In addition, more than 10 congressional committees have jurisdiction over the 21 federal agencies providing supports. This fragmentation creates service gaps, service overlaps, and sometimes conflicting objectives across programs. For example, the GAO noted that the Department of Education and the Department of Veteran's Affairs have separate programs that provide vocational rehabilitation supports to American Indians and veterans, respectively. Similar to Stapleton and Livermore (2011), GAO (2005a) concludes that the SSA income and CMS health support programs noted above were the system's major cost drivers.

Combined with the employment barriers it creates, the disability support system's fragmentation makes it difficult to design, test, and implement even modest employment innovations. For any intervention designed to modify supports across agencies, the sponsoring entity must first convince every agency with relevant authority to participate and coordinate with the test of the intervention-which can be quite difficult (Mann and Stapleton 2012). Hence, each individual program plods along, trying to improve its part of the overall system in ways that add up to very little overall progress. In reviewing evaluations of 27 federally sponsored employment programs, policies, and initiatives conducted since 2000, Livermore and Goodman (2009) found that many were not rigorously evaluated due, in part, to their limited focus and lack of a planned evaluation framework.

An additional issue is that some programs, particularly federal-state partnerships, are decentralized and do not have consistent metrics to measure progress across diverse areas, which is particularly important in the provision of employment and rehabilitation supports through state VR agencies. The United States Government Accountability Office (2005b) criticized the Department of Education, which oversees the state VR programs, for not having comprehensive measures to track state agency progress. Specifically, the GAO noted that the existing measures often tracked outcomes with considerable delays, 
and there were major challenges in comparing metrics across states given the diversity of VR target populations and variations in other state programs that provide employment supports.

Despite these challenges, there have been some rigorously evaluated return work demonstrations, which we summarize by sponsoring agency. ${ }^{3}$ The first, and largest, group includes evaluations of initiatives that have targeted volunteers who receive SSDI and SSI benefits. The second group consists of a recently implemented intervention by CMS to promote employment outcomes of those at risk of receiving disability benefits. The final group includes various agency evaluations of supported employment intervention programs, which are an alternative to traditional vocational supports for people with psychiatric disabilities. The distinguishing features of all of these initiatives include large samples, well-documented implementation, and the use of rigorous methods to assess outcomes. Hence, the findings from these initiatives provide credible evidence on the efficacy of approaches.

In reviewing the selected studies, we summarize the study's goals, target population, and impacts, then draw our own lessons for intervention design and evaluation of outcomes. The study's goals and target population provide important context for assessing the impacts from each intervention, particularly given how the fragmentation in program services and potential work disincentives described above might influence outcomes. We then summarize the impacts from each demonstration, focusing primarily on the employment outcomes and, if applicable, effects on earnings, benefit amounts, and caseload sizes. In some demonstrations, particularly those that focus on employment and other outcomes, we also discuss the potential net societal benefits, which would be accounted for in a full benefit-cost analysis (e.g., does the intervention have impacts in other areas, such as hospitalizations, that might reduce government spending elsewhere?). To facilitate comparisons across outcomes that span several years, we adjust earnings and benefit impact estimates for inflation using the Consumer Price Index (CPI) so that all estimates reflect 2012 dollars. In summarizing impact findings, we identify common themes associated with larger impacts that are related to the intervention design and target population that can inform future intervention efforts.

\section{Social Security demonstrations}

The largest evaluations of employment supports for people with disabilities have emphasized integrated approaches targeting people who receive SSDI and/or SSI. SSDI and SSI beneficiaries are a natural target population for services because they represent the largest federally funded cash transfer programs for people with disabilities, and because their use of VR services has traditionally been limited.

In 1980, Congress authorized the SSA to test SSDI demonstration projects over a fiveyear period and to test SSI demonstration projects permanently (Szymendera 2011). SSA could use this authority to temporarily waive certain program rules and allocate trust fund dollars and appropriated funds to finance demonstrations. The authority required that the demonstrations have sufficient scope and scale to ensure a thorough evaluation of the program or policy change under consideration.

The SSDI demonstration authority was renewed several times, most recently by the Ticket to Work (TTW) and Work Incentives Improvement Act of 1999 (Ticket Act), 
which was followed by the implementation of several demonstration projects and a major return to work program. ${ }^{4}$ Specifically, the Ticket Act established the TTW program, a program that provides SSDI and SSI beneficiaries with a voucher, or ticket, to purchase public or private sector employment services. One goal of the TTW program is to expand access to and choice of rehabilitation service providers available to SSI and SSDI beneficiaries beyond the traditional state VR services by allowing more public and private providers to offer supports to SSDI and SSI beneficiaries. A related goal was to develop provider incentives in a way that would tie the delivery of services to promote substantive earnings of beneficiaries. The combination of supports attempt to align provider and beneficiary incentives around employment. The Ticket Act also included provisions for other types of work supports and directed SSA to conduct demonstration projects in several areas, such as administering a benefit offset work incentive to increase the desirability of returning to work for SSDI beneficiaries. Although SSA's demonstration authority expired in 2005, the projects started before 2005 were allowed to continue.

As noted in the Ticket Act, even a small increase in exit rates from SSDI and SSI could result in large programmatic savings. The reason for the large potential savings is because most SSDI and SSI participants receive benefits for several years and the most likely reason for leaving the programs is either due to death or retirement. Annual exits from SSDI and SSI due to work have generally persisted at 0.5 percent for years, even in the face of numerous programmatic and economic changes (Berkowitz 2003, Newcomb et al. 2003). Based on this exit rate, the Ticket Act included the following language to motivate the rationale for employment interventions:

"If only an additional one-half of one percent of the current SSDI and SSI recipients were to cease receiving benefits as a result of employment, the savings to the Social Security Trust Funds and to the Treasury in cash assistance would total $\$ 3,500,000,000$ over the worklife of such individuals, far exceeding the cost of providing incentives and services needed to assist them in entering work and achieving financial independence to the best of their abilities."

Below, we provide a summary of evaluations for SSA employment initiatives implemented both before and after the Ticket Act. The pre-Ticket Act initiatives represent SSA's early efforts to implement demonstration projects, which proved that it was feasible to implement large-scale employment interventions using a randomized controlled trial design. The post-Ticket Act initiatives include several that were implemented to test a wide range of employment interventions targeting people with disabilities.

Perhaps not surprisingly given the severe impairment characteristics associated with SSDI and SSI program eligibility and the barriers to reform described above, most SSA employment demonstrations have struggled to recruit volunteer participants. Almost every intervention tested targeted people for services after they had met SSA's disability criteria and started receiving benefits. ${ }^{6}$ Although some interventions used program waivers, such as allowing beneficiaries to keep more of their benefits while working, in every demonstration, participants still could lose benefits for excess work. Most of these demonstration projects enrolled about five percent of the population targeted for recruitment (Rangarajan et al. 2008; Ruiz-Quintanilla et al. 2005), though more recent 
demonstrations with narrow target populations of youth and those with psychiatric impairment had higher participation rates of approximately 15 percent. As will be discussed in more detail below, the demonstrations with narrow target populations had customized service approaches, which likely made the services more appealing to participants, thereby increasing volunteer rates. Regardless, all intervention target populations represented a subgroup of all beneficiaries receiving SSDI and SSI.

\section{Demonstrations implemented before the Ticket Act}

In Table 1, we describe four major demonstrations that were implemented prior to the Ticket Act. The table includes a detailed summary of the evaluation design, intervention components, target population, and key impact findings related to employment, earnings, and program participation. Below, we describe each of these demonstrations in more detail.

In 1985, SSA funded its first large-scale demonstration, the Transitional Employment Training Demonstration (TETD). The TETD provided job placement, on-the-job training, and job retention services to eligible SSI claimants who were between ages 18 and 40, were diagnosed with an intellectual disability, and were living in one of the $13 \mathrm{dem}$ onstration communities. The demonstration included 745 eligible claimants who volunteered to participate. The intervention built off an earlier effort funded in 1981 called the Structured Training and Employment Transitional Services (STETS) demonstration, which was funded by the Department of Labor. The STETS demonstration showed strong promise in promoting employment for a limited sample of youth with disabilities. The TETD included a much larger sample of beneficiaries than did STETS (745 versus 467) in 13 demonstration communities, which allowed for a more rigorous evaluation of program impacts. The STETS study established the effectiveness of transitional employment supports in increasing employment among youth with disabilities (Kerachsky and Thornton 1987), and the TETD evaluation confirmed that these services improved employment rates and earnings (Decker and Thornton 1995).

The evaluation of TETD found that the program had impacts on employment, earnings, and benefit amounts that varied by subgroup and site (Decker and Thornton 1995). With slightly more than half employed at six years after follow-up, TETD treatment group members were 9 percentage points more likely to be employed relative to the control group. There was also a 70 percent increase in earnings over the six-year demonstration period, representing an \$8,969 (2012 dollars) total six-year increase in earnings. There were small declines in SSI and SSDI income benefit amounts, likely due to the increase in earnings, though the earnings increases were not substantial enough to move treatment group members off SSI and SSDI. ${ }^{7}$ Decker and Thornton (1995) found that the largest impacts on employment were among those with the highest IQ scores and those who were living independently (i.e., not in a sheltered setting, such as a facility). ${ }^{8}$ They also found that the sites that had the greatest impacts on employment and earnings across several participant groups made special efforts to tailor services to the needs of each participant. In contrast, projects that offered a more standardized intervention either were ineffective or effective for only a subset of participants. 
Table 1 Demonstrations and employment programs implemented before 2000

\begin{tabular}{|c|c|c|}
\hline $\begin{array}{l}\text { Demonstration } \\
\text { (Evaluation report) }\end{array}$ & Evaluation design & $\begin{array}{l}\text { Intervention } \\
\text { description }\end{array}$ \\
\hline $\begin{array}{l}\text { Structured Training } \\
\text { and Employment } \\
\text { Transitional Services } \\
\text { (STETS) (Department } \\
\text { of Labor) (Kerachsky } \\
\text { and Thornton 1987) }\end{array}$ & $\begin{array}{l}\text { Random assignment } \\
\text { demonstration } \\
\text { implemented } \\
\text { between November } \\
1981 \text { and December } \\
1982 \text { in five US cities. }\end{array}$ & $\begin{array}{l}\text { Intervention consisted } \\
\text { of three phases of } \\
\text { work interventions: (1) } \\
\text { an introductory work } \\
\text { exposure period, (2) } \\
\text { actual employment } \\
\text { with on-the-job } \\
\text { training (or supported } \\
\text { employment), and (3) } \\
\text { postemployment } \\
\text { follow-up and job } \\
\text { supports. }\end{array}$ \\
\hline
\end{tabular}

Target population/
sample

Summary of findings

Included 467 youth 22 -month

ages 18 to 24 who impacts

had IQ scores $\quad$ Percent

between 40 and $80 \quad$ employed

(many of whom

received SSI and/or Control: 19.0

SSDI benefits). percent

Treatment:

31.0 percent

supports.

Annualized

earnings

Control: $\$ 3,340$

Treatment:

$\$ 5,816$

Mean benefit

amounts

Control: $\$ 3,228$

Treatment:

$\$ 5,620$

Transitional

Employment

Training

Demonstration

(TETD) (Decker and

Thornton 1995)
Random assignment demonstration implemented between 1985 and 1987 in 13 demonstration communities.
Project NetWork (Kornfeld and Rupp 2000; Rupp and Bell 2003)
Random assignment demonstration implemented in eight sites around the country from 1992 to 1994.
Intervention included job placement, on-the -job training, and job-retention services. Treatment group members limited (one-year) jobplacement services or on-the-job training as part of the program. could receive time-

Included 745 SSI

beneficiaries who were between ages 18 and 40 and were

diagnosed with an intellectual disability.

Year 6 impacts

Percent

employed

Control: 41.8

percent

Treatment:

50.8 percent

Annualized

earnings

Control:

$\$ 12,514$

Treatment:

$\$ 21,483$

Benefit

amounts

Control mean:

$$
\$ 5,475
$$

Treatment mean: $\$ 5,137$

ntervention included intensive, employmentfocused casemanagement services to test the efficacy of case-management services in moving people with severe disabilities into full-time employment and off the disability rolls. Treatment group members received case-management services; control-group members remained eligible for any employment assistance in their communities.
Included 8,428 SSI

beneficiaries and applicants, as well as SSDI beneficiaries who were between ages 15 and 65, without regard to the nature of their disability.

Year 2 impacts

Percent

employed

Control: 13.6 percent

Treatment: 15.5 percent Annualized earnings

Control: $\$ 3,495$

Treatment: $\$ 3,850$ 
Table 1 Demonstrations and employment programs implemented before 2000 (Continued)

\begin{tabular}{|c|c|c|c|c|}
\hline \multirow{6}{*}{$\begin{array}{l}\text { State Partnership } \\
\text { Initiative (SPI) (Peikes } \\
\text { et al. 2005) }\end{array}$} & \multirow{6}{*}{$\begin{array}{l}\text { Random assignment } \\
\text { demonstration in four } \\
\text { projects in three } \\
\text { states implemented } \\
\text { from } 1999 \text { through } \\
2004 \text {. }\end{array}$} & \multirow{6}{*}{$\begin{array}{l}\text { The projects varied in } \\
\text { scope, but they all } \\
\text { generally provided } \\
\text { services in one of the } \\
\text { following approaches: } \\
\text { (1) improving } \\
\text { information about the } \\
\text { effect of work on } \\
\text { benefit receipt } \\
\text { (benefits counseling), } \\
\text { (2) encouraging the } \\
\text { use of available work } \\
\text { incentives, (3) testing } \\
\text { modifications to } \\
\text { program rules to allow } \\
\text { SSI beneficiaries to } \\
\text { earn and save more, } \\
\text { and (4) providing } \\
\text { better access to } \\
\text { vocational supports. }\end{array}$} & \multirow{6}{*}{$\begin{array}{l}\text { Included 3,366 SSDI } \\
\text { and SSI beneficiaries } \\
\text { in four random } \\
\text { assignment projects. }\end{array}$} & Year 1 impacts \\
\hline & & & & $\begin{array}{l}\text { Percent } \\
\text { employed } \\
\text { ranged across } \\
\text { sites from no } \\
\text { impact to }\end{array}$ \\
\hline & & & & $\begin{array}{l}\text { Control: } 27.1 \\
\text { percent }\end{array}$ \\
\hline & & & & $\begin{array}{l}\text { Treatment: } \\
44.1 \text { percent }\end{array}$ \\
\hline & & & & $\begin{array}{l}\text { No earnings } \\
\text { impacts, } \\
\text { though one } \\
\text { site had } \\
\text { negative } \\
\text { impacts on } \\
\text { earnings. }\end{array}$ \\
\hline & & & & $\begin{array}{l}\text { The SPI } \\
\text { evaluation did } \\
\text { not assess } \\
\text { effects on } \\
\text { cash disability } \\
\text { benefits. }\end{array}$ \\
\hline
\end{tabular}

Notes: The Department of Labor funded STETS. SSA was the lead agency on all other demonstrations. Adapted from Rangarajan et al. (2008). All dollar estimates are adjusted to the year 2012 using the Consumer Price Index, which is available at http://www.bls.gov/cpi/. We only present impacts that were statistically significant from zero at the 5 percent level.

Although TETD did not result in substantial savings to SSA, the evaluation suggested that participant benefits might have resulted in a net societal benefit. Specifically, the earnings gains of participants along with the likely reductions in outside service use offset most of the demonstration's costs. For example, Decker and Thornton (1995) found that the earnings gains of participating SSI recipients offset approximately 75 percent of TETD service costs and that the shift in service use away from expensive institutional supports used by control group members ("sheltered employment settings") could have offset the remaining TETD costs.

Project NetWork, implemented in 1991, used random assignment to evaluate an intervention that targeted a broad base of adult SSDI and SSI beneficiaries and applicants (Decker and Thornton 1995). The demonstration provided employment-focused case management services to test the efficacy of four different case management service models in moving people with severe disabilities into full-time employment and off the disability rolls. Project NetWork recruited 8,428 SSI claimants and applicants and SSDI claimants age 18 to 64 in eight sites around the country.

The findings from Project NetWork indicated initial impacts on employment that dissipated over time and varied by intervention model intensity. Rupp and Kornfeld (2000) found small employment impacts (approximately 2 percentage points) and annual earnings impacts (\$355 in 2012 dollars) in the second year of follow-up, though the size of impacts shrank by year three. With a longer follow-up period, Rupp and Bell (2003) found that small aggregate differences in earnings between treatment and control groups persisted during the six years following random assignment (though the annual difference in each individual year was not statistically significant). The relatively small impacts might reflect that the population recruited for Project NetWork was hard 
to employ; for example, only 14 percent of control group subjects were employed in the two years following random assignment, with annualized average earnings of $\$ 3,495$ (2012 dollars). In examining impacts by subgroups by intervention model, Kornfeld and Rupp (2000) found that the impacts were generally smallest in the least service intensive model that focused on providing case management services. This finding on the potential importance of intensity and customization of services was consistent with the subgroup findings noted above in TETD. Kornfeld and Rupp also noted that future interventions that target certain subpopulations with more intensive, ongoing supports might have the potential to generate larger impacts.

In 1999, SSA, in conjunction with the Department of Education, funded several projects under the State Partnership Initiative (SPI) to encourage innovative state practices that assist beneficiaries in reentering the workforce. These projects were evaluated using a combination of experimental and non-experimental designs. ${ }^{9}$ To measure impacts in the non-experimental sites, the evaluation team tested the strength of non-experimental methods using information from the experimental site. ${ }^{10}$ However, the evaluation team found that the non-experimental methods performed poorly in producing impact estimates for SPI (Peikes et al. 2008, Peikes et al. 2005). As a result, the evaluation team only chose to report findings from the four projects that used randomized controlled trial designs. ${ }^{11}$

For the four projects in three states (New Hampshire, New York, and Oklahoma) that used an experimental design, Peikes et al. (2005) found positive impacts on employment but no impacts on earnings. One possible explanation for the positive employment effect but lack of earnings impacts was that beneficiaries who received benefits counseling might have been more aware of the work disincentives through conversations with counselors and hence, despite overall increases in employment, chose to work on a limited basis so as to not jeopardize their benefit receipt. The authors emphasized using caution in drawing conclusions based on these short-term effects and suggested that longer-term follow-up data might provide a more complete picture of the interventions' effects. However, SSA did not conduct another follow-up study or a long-term benefit-cost analysis.

In summary, the four evaluations shown in Table 1 demonstrated to SSA the feasibility of implementing rigorous evaluations of employment interventions. Although some of these interventions had success in promoting employment and substantially improving participant outcomes, none demonstrated an ability to reduce SSA benefits or caseloads. Even TETD, the demonstration with the largest impacts on earnings, showed only small reductions in benefits amounts. In general, the interventions with the largest employment and earnings impacts provided customized supports to narrower target populations, particularly younger populations. In reviewing the limited outcomes from these demonstrations and other SSA demonstration efforts (some of which were canceled before completion), the GAO noted that these demonstrations were limited in scope and did not substantively inform policy development (GAO 2004). While not summarized above, the GAO report also critiqued several other SSA non-random assignment evaluations, many of which struggled to meet participation targets or were canceled due to administrative issues.

Although these four demonstrations did not result in caseload reductions, the evaluation findings did provide information that was used to plan future delivery of services. The STETS and TETD evaluations provided information on the effectiveness of providing transitional supports to youth with disabilities in more integrated settings that informed 
the development of later demonstrations such as the Youth Transition Demonstration (described below). Additionally, the SPI evaluation findings informed other SSA service delivery efforts, including a description for a national position to provide benefits counseling supports to all SSDI and SSI beneficiaries that were implemented after SPI (GAO 2008).

\section{SSA demonstrations and employment programs following Ticket Act}

Following the passage of the Ticket Act, SSA launched several major employment demonstration projects and programs. Some focused on the provision of employment supports, whereas others focused on the disability determination processes and the provision of health benefits. In designing these demonstration projects, SSA was interested in testing how the interventions influence the multiple work barriers faced by the heterogeneous SSDI and SSI beneficiary populations. Consequently, some interventions targeted rehabilitation supports (e.g., Ticket), whereas others attempted to provide enhanced work incentives and/or most customized supports to specific subgroups, such as those with psychiatric impairments and youth with disabilities. Although SSA implemented several projects after the Ticket to Work Act, we limit our review to the Ticket to Work program and three demonstrations that have a completed evaluation and included intervention components with a strong emphasis on work.

In Table 2, we describe three major demonstrations and the TTW program that was implemented following the Ticket Act. ${ }^{12}$ As in Table 1, Table 2 includes a detailed summary of the evaluation design, intervention components, target population, and key impact findings related to employment, earnings, and program participation. Below, we describe each of these three demonstrations and the TTW program in more detail.

In 1999, policymakers implemented the Ticket to Work program, which provides beneficiaries with more vendor choices for obtaining employment services and offers employment-support service providers new financial incentives to serve beneficiaries effectively. Specifically, TTW introduced a new, outcome-based financing system for employment service providers in both the public and private sectors. SSI and SSDI claimants who have been given tickets by SSA can select from an array of SSAapproved public and private providers, referred to as employment networks. Providers can decide whether or not to accept tickets from those seeking their services and determine, in consultation with the ticketholder, the types of services to be delivered. TTW was phased in nationally during three stages from 2002 through 2004.

During each stage, SSA sent notifications to all SSDI and SSI beneficiaries who were eligible for the program-which included the vast majority of caseload participants residing in specific groups of states. ${ }^{13}$

The TTW evaluation assessed impacts using a quasi-experimental approach that exploited variation in the implementation of TTW across states and over time. After controlling for characteristics in the pre-rollout year, Stapleton et al. (2008) measured impacts as the difference in outcomes between TTW-eligible beneficiaries living in states where TTW had been implemented and eligible beneficiaries who were living in states where the program had not yet been implemented. The strategy allowed each source of impact identification-cross-state, pre-post, and within-period cross-person-to be used in the estimation of impacts. 
Table 2 SSA demonstrations and employment programs implemented after 2000

\begin{tabular}{lll}
\hline $\begin{array}{l}\text { Demonstration } \\
\text { (Evaluation } \\
\text { report) }\end{array}$ & Evaluation design & $\begin{array}{l}\text { Intervention } \\
\text { description }\end{array}$ \\
\hline Ticket to Work & Non-experimental & Tickets (vouchers) to \\
(TTW) (Stapleton & evaluation initiated in & $\begin{array}{l}\text { select from SSA- } \\
\text { et al. 2008) }\end{array}$ \\
& three stages across & approved public and \\
& the US from 2002 & private providers. \\
& through 2004; & Providers can decide \\
& researchers can use & whether to accept \\
& the variation in the & tickets, and \\
& phased rollout to & beneficiaries can \\
& evaluate impacts on & work with providers \\
& service use, earnings, & to determine the \\
& and benefit receipt. & types of services \\
& & needed.
\end{tabular}

Benefit Offset Random assignment

Pilot

Demonstration

(BOPD)

(Weathers and

Hemmeter 2011)

\section{demonstration} implemented in 2005 in four demonstration states. a gradual income \$1 for SSDI beneficiaries earning above SGA.
Intervention included benefit offset of $\$ 2$ to

Included SSDI beneficiaries who did

\section{Target population/ Summary of sample findings}

Tickets were mailed to most SSDI and SSI beneficiaries.

Impact estimates

from early stages of the rollout for earnings and benefit amounts were too small to differentiate from historical variation in these outcomes.

No aggregate employment or earnings impacts. BOPD had mixed effects on earnings depending on whether the volunteer earned above or below SGA.

Benefit payments (year 2)

Treatment: $\$ 11,339$

Control: $\$ 10,757$

Mental Health Random assignment Treatment Study demonstration in 23 (MHTS) (Frey et al. 2011) projects in sites throughout the country implemented medication from 2006 through 2010

Treatment: 61 ntervention included supported employment and systematic

management services over a 24-month period.

Included 2,238 SSDI beneficiaries with a primary impairment of schizophrenia or affective disorder.

Percent employed (24 months)

Control: 40 percent percent

Average earnings (past month earnings averaged over eight interviews)

Control: \$97

Treatment: \$148

Percent employed

Intervention varied Included according to site but approximately 880 included services such as job coaching, employment supports, and benefits counseling.

high impact (West youth ages 14 to 25

per site who receive SSA disability benefits or who are at risk of receiving such benefits after leaving school. ranged across sites

from no impact to

Virginia)

Control: 23.6 percent

Treatment: 42.7

percent

Annualized earnings

impacts ranged

across site from no

impact to:

Control: $\$ 1,035$

Treatment: $\$ 1,559$

Notes: Adapted from Rangarajan et al. (2008). All dollar estimates are adjusted to the year 2012 using the Consumer Price Index, which is available at http://www.bls.gov/cpi/ (accessed March 25, 2013). We only present impacts that were statistically significant from zero at the 5 percent level. 
The impact estimates from the evaluation showed the effects of TTW on employment and benefits were too small to differentiate from historical trends and there were only small effects, on service enrollment. Stapleton et al. (2008) found that TTW increased beneficiary use of employment services in 2002 and 2003, the first two rollout years. However, the increase in service utilization did not appear to produce a corresponding increase in beneficiary earnings or a reduction in benefit payments, as the variation in these outcomes were too small to differentiate from historical variation. ${ }^{14}$ The authors noted that impacts for 2004 and later may be larger as participation rates continue to increase. Nevertheless, analysis of trends suggests that to generate the level of exits from the SSA disability programs originally envisioned by the authorizing legislation, TTW needs to induce shifts in beneficiary behavior that are much larger than what has been observed so far.

A major challenge in establishing TTW was creating a new market of service providers from the private sector. Traditionally, these services had been provided to beneficiaries through state VR agencies, and the hope was that the TTW would offer more alternatives for obtaining services through private providers. However, even following the passage of the Ticket Act, the vast majority of participants used their tickets at state VR agencies, in large part because few providers entered the market, and the ones that did found the payments from SSA to be limited relative to the costs of serving the few clients that did bring Tickets to them.

In reviewing the implementation of TTW, GAO (2004) argued that the rush to implement the program created inefficiencies that could have been addressed in a smaller pilot. GAO claimed that if SSA had tested various components of the TTW program prior to launching it nationwide, it might have been able to identify problems and develop solutions prior to implementation. GAO also cited the lack of tests involving VR service-related interventions prior to TTW as a shortcoming in informing the development of TTW. In 2008, the TTW program regulations were revised in an attempt to address initial shortcomings of the program. A primary goal of the revised regulations was to increase the financial incentives for employment service providers to serve ticketholders and thereby increase the pool of service providers available to TTW participants (Altshuler et al. 2011).

The benefits of developing a pilot program prior to a major demonstration are illustrated by SSA's Benefit Offset Pilot Demonstration (BOPD), which was the precursor to the larger and ongoing Benefit Offset National Demonstration (BOND). BOPD was implemented in four states (Connecticut, Utah, Vermont, and Wisconsin) to test the administrative processes needed for BOND. As in BOND, BOPD provided SSDI beneficiaries with a gradual income benefit offset of $\$ 2$ for every $\$ 1$ in earnings above SGA instead of withdrawing all income benefits for any earnings above SGA, as under current law. Although all BOPD sites adhered to broad participation and recruitment requirements, the target population and outreach and recruitment methods varied considerably by state. Unlike BOND, BOPD only included volunteers.

Weathers and Hemmeter (2011) found mixed employment, earnings, and benefit effects depending on whether beneficiaries earned above SGA before the demonstration. Specifically, they found that BOPD had a significant positive impact on earnings for those earnings below SGA. However, they found that BOPD had a negative effect on the earnings of those already earning above SGA. The former finding reflects that some 
people responded to the enhanced work incentive by increasing their labor force participation, suggesting that the current law causes some beneficiaries to restrict their earnings. The latter finding indicates that those already earning above SGA might reduce their earnings in response to the benefit offset because it allows the beneficiaries to maintain their overall income level while working fewer hours. The combined effect of those increasing and those decreasing their earnings in response to the benefit offset led to a net increase in program costs, as benefit payments increased by over $\$ 1,000$ per volunteer over the two-year period. Weathers and Hemmeter emphasized that the findings are for volunteers and therefore do not necessarily imply that BOND will produce similar findings.

In addition to providing a potential preview of BOND's impacts, BOPD revealed challenges in administering the benefit offset that would be eventually used to inform the administration of the benefit offset under BOND. The initial benefit adjustment and payment process, which differed across the four BOPD sites, created significant delays in benefit payments to offset users. The lessons learned during BOPD resulted in the creation of a centralized payment system for BOND's benefit offset users. The BOND project is currently under way in 10 sites across the country.

The final two demonstrations were geared toward subgroups of beneficiaries based on impairment type (psychiatric disabilities) and age (young adults). To encourage SSDI beneficiaries with a primary impairment of schizophrenia or affective disorder to work, SSA conducted the Mental Health Treatment Study (MHTS) from 2006 to 2010. MHTS provided supported employment (SE) and systemic medication management services (MMS) to a randomized group of volunteer participants over a 24-month period. The SE intervention was administered at sites chosen because of their ability to implement the Individual Placement and Support (IPS) model—the evidence-based SE model used for the MHTS SE intervention-as well as other behavioral health and SE services. As will be described in more detail in the next section, the IPS model has demonstrated repeated success providing services to those with psychiatric impairments. The MMS intervention was composed of two parts: a systemic review of symptoms and functioning by an experienced nurse prior to each prescriber visit and an "algorithmic approach" to MMS that employed diagnosis specific decision trees.

Frey et al. (2011) found that the MHTS improved several employment, earnings, and health outcomes for treatment group members and that participation rates were generally strong among those offered services. Frey et al. noted that the strong participation rates (14 percent of those solicited participated) potentially reflect high unmet demand for these types of services. After 24 months, 61 percent of those who received MHTS services were employed, compared with just 40 percent of those who did not receive the services. The findings from a follow-up survey indicated small monthly earnings impacts of just over $\$ 50$, though the average monthly earnings of treatment group members were still quite low (\$148). Compared with control subjects, treatment subjects were more likely to use both medical and vocational services. The treatment group also reported improvements in mental health status and quality of life. However, these benefits came at significant intervention cost, as each treatment group member received $\$ 6,986$ worth of services each year. Although the demonstration did not conduct a formal benefit-cost analysis, Frey et al. (2011) noted that MHTS had impacts in other areas that would be important in assessing the net benefits of the demonstration. For example, MHTS created important 
service linkages to ensure that beneficiaries received and adhered to their prescription drug medication, as well as provided other mental health supports that had impacts elsewhere, including reduced hospitalizations.

Between 2003 and 2008, SSA initiated a multisite intervention called the Youth Transition Demonstration (YTD) projects, which provided services to youth between the ages of 14 to 25 who were receiving SSI or SSDI benefits, or at risk of entering SSI or SSDI. In total, 10 projects were implemented, but only six have a formal assessment of impacts. The six sites use a randomized controlled trial evaluation design to assess outcomes one year and three years after enrollment. The types of services offered to participants vary by project, but all projects include the following two components: (1) a core intervention that emphasizes employment as a key outcome and (2) services, such as intensive employment supports and benefits counseling, that are tailored to the unique needs of youth who receive SSA disability benefits (Luecking and Wittenburg 2009).

The one-year follow-up findings from the six random assignment sites indicate that all interventions led to increased use of employment services, though the intensity of service utilization varied by implementation phase (Fraker 2013). A key aspect of the YTD design was the staggered intervention of sites that included the implementation of three projects in Phase 1 and three more projects in Phase 2. Before the Phase 2 projects were initiated, an implementation analysis of Phase 1 projects was conducted and revealed a need for closer monitoring of both the delivery of paid employment services and participant outcomes. The increased monitoring yielded positive results for Phase 2 projects in comparison to the services delivered in Phase 1 projects-the average number of hours received for any type of participant service was consistently high for these projects.

The initial YTD findings indicated a potential relationship between service intensity and employment impacts. Of the four projects that provided the most hours of services, three had positive impacts on the number of youth who found paying jobs, and two also had positive impacts on annual earnings. In contrast, the two projects that provided the fewest hours of services had no impacts on employment and earnings.

The two YTD sites with large impacts are particularly notable given their size and nature of interventions. The Miami-Dade County and West Virginia sites had statistically significant positive impacts on both paid employment and total earnings during the year after random assignment. Forty-three percent of the treatment group in West Virginia was employed, reflecting an impact of 19.1 percentage points. The impact on mean annual earnings was $\$ 524$ in that site (relative to control group earnings of $\$ 1,035)$. In Miami-Dade County, the impacts on paid employment and earnings were 9.4 percentage points and $\$ 306$, respectively. The only Phase 2 project that did not have impacts was in Montgomery County (Maryland), which, unlike the other sites, did not have a target population of SSI or SSDI youth. In the final evaluation report of this site, Fraker et al. (2012) found that the control group still had access to very strong support services, which likely contributed to the high employment rates of the control group (and lack of impacts).

In summary, the post-Ticket Act demonstration projects and programs indicated a mix of success in promoting employment outcomes. As with the findings for earlier SSA demonstrations projects, the MHTS and YTD interventions, which offered more 
customized supports to more narrowly targeted interventions, had relatively stronger impacts programs and demonstrations such as TTW and BOPD, which had less individually targeted approaches in targeting participants for services.

An important caveat for the interventions described above is that it is too early to assess long-term impacts that could have important implications for assessing the costs and benefits of the demonstration. For example, there is a potential that some demonstrations could produce a net benefit on participant outcomes and spending by other government agencies, even if there is not a direct reduction on spending for SSDI and SSI if the demonstrations result in less government spending elsewhere. This issue is particularly relevant in YTD and MHTS, given that the positive participant outcomes related to employment and employment service use could lead to other improved longterm outcomes (such as social engagement), leading to a lower need for future services or use of expensive supports (e.g., Medicare payments in MHTS or lower incarceration rates in YTD).

\section{CMS' Demonstration to Maintain Independence and Employment}

In an attempt to examine the effectiveness of alternative approaches in providing supports to people with disabilities to improve their employment outcomes, the Ticket to Work and Work Incentives Improvement Act of 1999 legislated the test of an initiative that extends Medicaid coverage to individuals who are at risk of-but may have not yet applied for-SSA disability benefits. The test of this intervention was named the Demonstration to Maintain Independence and Employment (DMIE) and was administered by CMS.

The DMIE was a multisite randomized controlled trial designed to examine the effects of behavioral health, case management, vocational, and other services on economic and health outcomes of working individuals with potentially disabling behavioral health disorders, including those who were not SSI or SSDI beneficiaries (Table 3). Consistent with the authorizing legislation, the DMIE's primary intervention was the provision of health insurance to populations at risk of receiving SSA disability benefits. All participating states used random assignment, offered the program to eligible adults 18 to 62 years old who were working at least part time, and excluded persons who indicated that they had pending disability applications or were receiving SSDI or SSI benefits. In general, all states

Table 3 CMS interventions to promote employment and independence

\begin{tabular}{|c|c|c|c|c|}
\hline $\begin{array}{l}\text { Demonstration } \\
\text { (Evaluation } \\
\text { report) }\end{array}$ & Evaluation design & $\begin{array}{l}\text { Intervention } \\
\text { description }\end{array}$ & $\begin{array}{l}\text { Target population/ } \\
\text { sample }\end{array}$ & $\begin{array}{l}\text { Summary of } \\
\text { findings }\end{array}$ \\
\hline $\begin{array}{l}\text { Demonstration to } \\
\text { Maintain } \\
\text { Independence } \\
\text { and Employment } \\
\text { (DMIE) (Whalen } \\
\text { et al. 2011) }\end{array}$ & $\begin{array}{l}\text { Random assignment } \\
\text { demonstration } \\
\text { implemented in four } \\
\text { states (Texas, } \\
\text { Minnesota, Kansas, } \\
\text { and Hawaii) from } \\
2006 \text { through } 2008 \text {. }\end{array}$ & $\begin{array}{l}\text { Intervention varied by } \\
\text { site. All states } \\
\text { provided } \\
\text { "wraparound" health } \\
\text { services } \\
\text { supplementing } \\
\text { existing coverage, } \\
\text { employment supports, } \\
\text { and person-centered } \\
\text { case management. }\end{array}$ & $\begin{array}{l}\text { Included working } \\
\text { individuals with } \\
\text { potentially disabling } \\
\text { behavioral health } \\
\text { conditions ages } 18 \\
\text { to } 62 \text {. Participants } \\
\text { included both SSI/ } \\
\text { SSDI beneficiaries } \\
\text { and nonbeneficiaries. }\end{array}$ & $\begin{array}{l}\text { No employment } \\
\text { impacts. Earnings } \\
\text { impacts not } \\
\text { measured. } \\
\text { Declines in SSA } \\
\text { benefit receipt of } 2 \\
\text { percentage points } \\
\text { in one site (Texas) } \\
\text { (4.0 treatment } \\
\text { group vs. } 2.0 \text { for } \\
\text { control group). }\end{array}$ \\
\hline
\end{tabular}

Notes: All dollar estimates are adjusted to the year 2012 using the Consumer Price Index, which is available at http:// www.bls.gov/cpi/ (accessed March 25, 2013). We only present impacts that were statistically significant from zero at the 5 percent level. 
provided "wraparound" health services supplementing existing coverage, employment supports, and person-centered case management. The general goal of these interventions was to promote health and reduce long-term reliance on SSDI and SSI. Each of the four participating states-Kansas, Hawaii, Minnesota, and Texas-developed its own intervention, target population, and recruitment methods within CMS guidelines. An important difference across states was that primary disabling conditions varied; Kansas enrolled individuals with a wide array of conditions, Minnesota and Texas focused on adults with mental/behavioral health issues, and Hawaii targeted people with diabetes.

The DMIE evaluation found that the intervention's effects varied by site and were particularly sensitive to the target population (Whalen et al. 2011). None of the DMIE projects had an impact on employment and earnings. A major challenge in detecting employment and earning impacts was that control group members in all sites generally remained employed (over 90 percent) throughout the demonstration. The DMIE was associated with a statistically significant reduction of 2.0 percentage points in receipt of SSA benefits in Texas. The authors noted that the short time frame may have limited impacts, particularly on SSA disability benefits given that it takes some time to apply for and become eligible for these benefits.

DMIE is notable because it represented an attempt to target services to people with disabilities before they entered SSDI or SSI, though the findings reveal the challenges of identifying a target population at risk for benefits. In all sites, most of the control group remained employed throughout the demonstration, and the one site that had impacts on SSDI participation had very low rates of SSDI entry by the control group (4.0 percent), limiting the potential effect size. If future interventions could more precisely identify populations at risk for program entry or loss of employment, then early intervention impacts might be stronger than those reported for DMIE.

\section{Other demonstrations}

There have been initiatives outside of SSA and CMS to help people with disabilities work. However, most of these have not been rigorously evaluated (Rangarajan et al. 2008). Consequently, many service providers continue to use more traditional approaches to providing employment services-especially sheltered and segregated approaches-to people with intellectual and other severe disabilities, in part because a universally agreed upon set of best practices for serving this population does not exist (Kregel and Dean 2002).

The one employment intervention that has been rigorously evaluated outside of SSA and CMS is supported employment programs for people with psychiatric disorders (including affective, anxiety, and schizophrenia disorders; Table 4). These programs are voluntary and generally offer a combination of competitive employment and health services to populations that are recruited through social service agencies. ${ }^{15}$ During the 1990s, several independent evaluations found significant impacts of supported employment interventions on employment outcomes of people with psychiatric impairments (Bond 2004). Each of these evaluations provided a rigorous evaluation of employment outcomes and included detailed documentation of the services delivered so the findings could be replicated in other settings. The follow-up period on these studies typically was one to three years, and sample sizes tended to be small (from less than 50 to over 200). Bond (2004) summarized 12 randomized controlled studies that compared supported 
Table 4 Supported employment ilnitiatives targeting people with psychiatric disorders

\begin{tabular}{|c|c|c|c|c|c|}
\hline $\begin{array}{l}\text { Demonstration } \\
\text { (Evaluation } \\
\text { report) }\end{array}$ & $\begin{array}{l}\text { Evaluation } \\
\text { design }\end{array}$ & $\begin{array}{l}\text { Intervention } \\
\text { description }\end{array}$ & $\begin{array}{l}\text { Target } \\
\text { population/ } \\
\text { sample }\end{array}$ & $\begin{array}{l}\text { Employment } \\
\text { and earnings } \\
\text { estimates }\end{array}$ & $\begin{array}{l}\text { Summary of } \\
\text { findings }\end{array}$ \\
\hline \multirow{4}{*}{$\begin{array}{l}\text { Supported } \\
\text { Employment } \\
\text { Model - } \\
\text { summary of } \\
\text { independent } \\
\text { studies (Bond } \\
\text { 2004; Bond et al. } \\
\text { 2005) }\end{array}$} & \multirow{4}{*}{$\begin{array}{l}\text { Random } \\
\text { assignment } \\
\text { evaluations of } 12 \\
\text { supported } \\
\text { employment } \\
\text { interventions that } \\
\text { were } \\
\text { summarized by } \\
\text { Bond et al. } \\
\text { (2005), which } \\
\text { were originally } \\
\text { conducted by } \\
\text { nine research } \\
\text { teams in various } \\
\text { geographic } \\
\text { regions } \\
\text { representing } \\
\text { both rural and } \\
\text { urban } \\
\text { communities. }\end{array}$} & \multirow{4}{*}{$\begin{array}{l}\text { In the } 12 \text { studies } \\
\text { reviewed, the } \\
\text { most common } \\
\text { supported } \\
\text { employment } \\
\text { model tested was } \\
\text { the Individual } \\
\text { Placement and } \\
\text { Support (IPS) } \\
\text { model (see } \\
\text { Rangarajan et al. } \\
\text { 2008 for more } \\
\text { details on this } \\
\text { model), which } \\
\text { was compared } \\
\text { with groups that } \\
\text { usually had } \\
\text { access to } \\
\text { standard } \\
\text { practices. }\end{array}$} & \multirow{4}{*}{$\begin{array}{l}\text { Number of } \\
\text { participants } \\
\text { varied by study, } \\
\text { but all studies } \\
\text { included people } \\
\text { with psychiatric } \\
\text { impairments who } \\
\text { were generally } \\
\text { recruited by } \\
\text { social service } \\
\text { agencies. }\end{array}$} & $\begin{array}{l}\text { Percent } \\
\text { employed: }\end{array}$ & \multirow{4}{*}{$\begin{array}{l}\text { Average } \\
\text { competitive } \\
\text { employment rate } \\
\text { for consumers in } \\
\text { supported } \\
\text { employment was } \\
\text { more than } 250 \\
\text { percent larger } \\
\text { than that of } \\
\text { control group } \\
\text { members. The } \\
\text { summary did not } \\
\text { assess the } \\
\text { earnings levels or } \\
\text { cash disability } \\
\text { receipt. }\end{array}$} \\
\hline & & & & $\begin{array}{l}\text { Control: } 23 \\
\text { percent }\end{array}$ & \\
\hline & & & & $\begin{array}{l}\text { Treatment: } 61 \\
\text { percent }\end{array}$ & \\
\hline & & & & $\begin{array}{l}\text { No earnings } \\
\text { estimates }\end{array}$ & \\
\hline \multirow{6}{*}{$\begin{array}{l}\text { Employment } \\
\text { Intervention } \\
\text { Demonstration } \\
\text { Program (EIDP) } \\
\text { (Cook et al. } \\
\text { 2008) }\end{array}$} & \multirow{6}{*}{$\begin{array}{l}\text { Random } \\
\text { assignment } \\
\text { evaluation of the } \\
\text { effectiveness of } \\
\text { several } \\
\text { experimental } \\
\text { supported } \\
\text { employment } \\
\text { programs for } \\
\text { people with } \\
\text { psychiatric } \\
\text { disabilities in } \\
\text { seven locations } \\
\text { across the United } \\
\text { States from } 1995 \\
\text { to } 2003 \text {. }\end{array}$} & \multirow{6}{*}{$\begin{array}{l}\text { The treatment } \\
\text { group received } \\
\text { services delivered } \\
\text { by various } \\
\text { entities under } \\
\text { different } \\
\text { supported } \\
\text { employment } \\
\text { service models } \\
\text { designed for } \\
\text { people with } \\
\text { psychiatric } \\
\text { disabilities. Other } \\
\text { experimental sites } \\
\text { enhanced their } \\
\text { service model by } \\
\text { providing unique } \\
\text { features such as } \\
\text { developing } \\
\text { special } \\
\text { connections to } \\
\text { employers. All } \\
\text { interventions } \\
\text { shared common } \\
\text { characteristics of } \\
\text { supported } \\
\text { employment } \\
\text { program models. }\end{array}$} & \multirow{6}{*}{$\begin{array}{l}\text { 1,273 participants } \\
\text { with psychiatric } \\
\text { impairments. }\end{array}$} & $\begin{array}{l}\text { Percent } \\
\text { employed: }\end{array}$ & \multirow{6}{*}{$\begin{array}{l}\text { Individuals } \\
\text { enrolled in } \\
\text { supported } \\
\text { employment } \\
\text { programs were } \\
62 \text { percent more } \\
\text { likely to be } \\
\text { competitively } \\
\text { employed than } \\
\text { their } \\
\text { counterparts. } \\
\text { Supported } \\
\text { employment } \\
\text { participants had } \\
23 \text { percent } \\
\text { higher monthly } \\
\text { earned income } \\
\text { (Cook et al. 2005) }\end{array}$} \\
\hline & & & & $\begin{array}{l}\text { Control: } 34 \\
\text { percent }\end{array}$ & \\
\hline & & & & $\begin{array}{l}\text { Treatment: } 55 \\
\text { percent }\end{array}$ & \\
\hline & & & & $\begin{array}{l}\text { Annualized } \\
\text { earned } \\
\text { income: }\end{array}$ & \\
\hline & & & & $\begin{array}{l}\text { Control: } \\
\$ 1,315\end{array}$ & \\
\hline & & & & $\begin{array}{l}\text { Treatment: } \\
\$ 1,621\end{array}$ & \\
\hline
\end{tabular}

Source: Summary adapted from Rangarajan et al. (2008).

employment with established vocational services, and Bond et al. (2008) summarized 11 studies with similar requirements as well as high fidelity to the IPS supported employment model. A major advantage of the IPS model relative to other models was that it has been well documented in a practice manual (Becker and Drake 2003).

The supported employment findings in these small-scale studies consistently showed strong impacts on employment. Bond et al. (2005) found that the average competitive employment rate was 59 percent for consumers in supported employment, compared with 21 percent for those not receiving supported employment services. In the later studies focusing on the IPS model, Bond et al. (2008) found 
comparable employment rate effects of 61 percent for treatment participants and 23 percent for control participants. Bond et al. (2008) also examined four studies that assessed hours worked, finding that 44 percent of treatment participants were employed for 20 hours or more a week compared to 14 percent of control participants. Although the studies provided important information on employment, they tested different types of service models and lacked information on key outcomes, such as earnings.

To provide a more comprehensive evaluation of alternative supported employment models in different settings on several outcomes (including earnings), in 1995, SAMHSA funded the Employment Intervention Demonstration Program (EIDP) in several cities. A major advantage of EIDP over the previous studies is that it was structured to provide a detailed comparison across supported employment models, regions, and subgroups. The study was designed to determine new ways of enhancing employment opportunities and quality of life for consumers with psychiatric conditions. The treatment groups received services under different supported employment service models designed specifically for people with psychiatric conditions, including the IPS model described above, whereas other experimental sites enhanced their service model by providing novel features such as developing special connections to employers. Although the program models varied, all shared common characteristics of supported employment models, including a focus on integration of clinical and employment services, availability of ongoing support, development of jobs consistent with the person's career ambitions, and a focus on rapid job placement. There were 1,273 participants assigned to treatment and control groups at the EIDP study sites, and the evaluation tracked outcomes for two years.

As with the supported employment findings of the 1990s, Cook et al. (2005) continued to find that supported employment models were successful in promoting better employment and earnings outcomes for people with psychiatric impairments. Specifically, Cook et al. (2005) reported that individuals enrolled in supported employment programs were more likely to be competitively employed than their counterparts (55 versus 34 percent) and work 40 or more hours per month (51 versus 39 percent). Cook et al. (2005) also found that supported employment participants had higher monthly earnings, though earnings were modest ( $\$ 122$ versus $\$ 99$ per month). Although the earnings impacts in these studies were statistically significant and represented significant increases in monthly income, they were generally not enough to move people off benefits.

One recurring theme in the supported employment findings that was consistent with the SSA demonstrations was the importance of customized supports to meet the needs of the individuals. Specifically, Cook et al. (2005) found models that had a more integrated set of vocational services and clinical mental health services, such as medication management and individual therapy, were more effective than models with low levels of service integration. Participants in the more integrated models were over twice as likely to be competitively employed and almost one-and-one-half times as likely to work 40 or more hours per month (Cook and O'Day 2006). They noted the results confirm the importance of communication between service providers, integration of mental health and rehabilitation services, and a strong emphasis on vocational services in meeting employment goals. 


\section{Discussion}

Over the past few decades, the employment interventions for people with disabilities have experienced mixed success in promoting employment and earnings outcomes and little success in reducing reliance on SSI and SSDI benefits. The size of employment and earnings impacts are relatively small in comparison to what might be needed to eliminate the need for SSDI or SSI benefits (and the associated benefits through Medicare and Medicaid). In part, the limited impacts likely reflect that most participants targeted in these demonstrations receive substantial cash and other supports that are terminated due to substantive work and must navigate a fragmented system of supports to access additional services.

Based on existing findings, the strongest interventions appear to customize supports and target services specifically to younger populations, which is perhaps not surprising given that younger populations have long-term work potential. For example, the supported employment and MHTS interventions targeted customized supports to those with psychiatric impairments and repeatedly generated small, but significant, positive impacts in a variety of employment settings. Several youth projects, including the STETS and TETD demonstrations and three ongoing YTD projects, showed strong employment and earnings impacts, particularly in projects where the supports were individually customized. Conversely, employment impacts have generally been smaller for interventions with a broader focus or where the supports did not substantially differ from existing services. For example, TTW offers an employment-based program to the majority of SSDI and SSI eligible beneficiaries that-from the beneficiary or private employment provider perspective-at initial rollout was not radically different from the supports that were previously available.

Another lesson that these demonstrations illustrate is the importance of testing intervention service delivery prior to full-scale implementation to ensure everything operates as intended. BOPD and YTD both provide excellent examples of how testing and careful monitoring of intervention services can lead to improvements in service delivery. Conversely, the lack of testing in TTW led to substantial initial implementation problems.

As policymakers continue to develop ideas to promote the employment and economic self-sufficiency of people with disabilities, the lessons from past and ongoing employment demonstrations are providing insights into promising interventions. For example, findings from YTD and other demonstrations are shaping the development of the Promoting Readiness of Minors in SSI (PROMISE) intervention, which seeks to improve the provision and coordination of services to promote better education and employment outcomes for child SSI beneficiaries. ${ }^{16}$ However, if policymakers wish to discover interventions that reduce caseloads as well as improve employment and earnings outcomes, they will likely need to test more ambitious ideas that address the major work barriers within the current system. ${ }^{17}$ Unfortunately, there is little information on how such major reforms would affect the outcomes of people with disabilities, though based on the findings of DMIE, they will need a strong mechanism to identify a target population at risk for benefit receipt. Nonetheless, the successes identified in this review of intervention options, particularly those assisting younger beneficiaries, hold promise for designing future approaches. Perhaps more importantly, the general approach of testing intervention supports to ensure adequate implementation and interest in participation prior to full-scale 
implementation is fundamental to ensuring that any new initiatives do not have unintended consequences.

\section{Endnotes}

${ }^{1} \mathrm{CMS}$ provides administrative oversight for Medicare, which is fully federally funded, and Medicaid, which uses a mix of federal and state dollars.

${ }^{2}$ When a state VR agency does not have enough funding, it uses a waiting list process called order of selection, where cases are prioritized based on their disability status.

${ }^{3}$ It is important to note that employment interventions are part of a much broader literature that examines the work and program participation outcomes of people with disabilities. The related literature includes assessments of the residual work capacity of SSDI beneficiaries (Maestas et al. 2011; Von Wachter et al. 2011) factors that influence general work and program participation trends (Stapleton and Burkhauser 2003), and dynamic structural models that examine how SSDI beneficiaries' behavioral outcomes change in response to different work incentives (Benítez-Silva et al. 2006, Benítez-Silva et al. 2010).

${ }^{4}$ The Ticket Act also allowed states to establish Medicaid buy-in programs that allow persons to maintain their medical coverage while working and extended Medicare coverage for working SSDI beneficiaries.

${ }^{5}$ For more details, see http://ssa.gov/OP_Home/comp2/F106-170.html (Accessed April 30 2013).

${ }^{6}$ As will be described, two demonstrations did not exclusively recruit people who had already enrolled in the SSA disability programs. Project Network targeted a subgroup of beneficiaries applying for benefits. Additionally, a Youth Transition Demonstration project at one site targeted youth with disabilities who were not receiving SSI or SSDI benefits. However, in both cases, the subgroup of people not on the disability rolls represented a small portion of the demonstration target population.

${ }^{7}$ Average SSI benefits were reduced by $\$ 1,645$ over the six-year period after enrollment. Among the subgroup that received SSDI benefits at the time of enrollment, the statistically significant impact on SSDI receipt was about 11 percent at the end of the six-year post enrollment period (Decker and Thornton 1995).

${ }^{8}$ In TETD, there were statistically significant differences in impacts across subgroups based on the IQs of youth. The estimates suggest that the demonstration was particularly effective in increasing earnings for the group with the highest IQ scores but ineffective for groups with low or moderate scores. The estimated impact on earnings for people living independently at the time of enrollment was very large (189 percent), which possibly reflects their greater independence or motivation (Decker and Thornton 1995).

${ }^{9}$ The original SPI projects included 18 projects in 17 states from 1999 to 2004 that delivered employment-related services to people with disabilities. SSA funded 12 of the 18 state projects, and the Department of Education Rehabilitation Services Administration (RSA) funded the remaining six. The SSA-funded projects focused on testing new services for the Social Security claimants with disabilities. The RSA-funded projects focused on activities aimed at changing the overall system of supports for people with disabilities (some of whom received other forms of public assistance) and were designed to help them 
obtain employment and live independently. One of the 12 SSA-funded projects that targeted high school students with an emphasis on education and employment aspirations was excluded from the study because the administrative data for the project was not sufficient for measuring impacts on these outcomes.

${ }^{10}$ Specifically, they tested the feasibility of using propensity score matching in the non-experimental sites, where the characteristics of treatment group members were matched to a comparison group using administrative data. To test this method, they compared findings from the propensity score matching methodology to the random assignment findings in the four sites that had implemented random assignment. Presumably, if the propensity score matching method was unbiased, it would produce results similar to those based on random assignment.

${ }^{11}$ This problem in finding a non-experimental comparison group illustrates a general problem in using non-experimental methods to generate impact estimates when volunteer rates are low (i.e., below 5 percent); namely, participant and nonparticipant characteristics vary in ways that cannot be observed. Hence, this finding might be important in considering the applicability of non-experimental designs more generally in other settings where volunteer rates are low.

${ }^{12} \mathrm{GAO}$ (2008) noted that since 1998, SSA had initiated 14 demonstration projects that had a wide range of activities. We chose interventions that had an intensive employment focus and a completed evaluation. At the time of their review, five projects had been canceled and only four were complete. Of the completed demonstrations, we only exclude the Accelerated Benefits demonstration, which, although it had an employment component, had the dominant provision of providing early access to a health plan to SSDI beneficiaries in the Medicare waiting period. The employment supports in the Accelerated Benefits demonstration, which were delivered telephonically, were substantially less intensive relative to the employment supports described in this section.

${ }^{13}$ The only adult beneficiaries who were ineligible for TTW were (1) those designated as "medical improvement expected" who had been on the rolls for less than three years and had not yet had a continuing disability review and (2) former child SSI recipients awaiting adult redetermination.

${ }^{14}$ They did find initial small impacts on benefit and earnings outcomes, but in testing the sensitivity of their results, they found that the small effects were not different from the effects during the pre-periods when TTW was not available. Hence, they concluded the effects were too small to differentiate from historical variation.

${ }^{15}$ According to Wehman and Revell (2005), funding for supported employment services typically occurs in two phases: (1) employment services funded by VR and several other federal and state agencies on a time-limited basis that may include vocational assessment, career planning, job development, job-site training, assistive technology, and accommodations; and (2) if available, the provision of extended services (for example, employment supports and case management) to support work performance. Variations of supported employment models exist, including for people with nonpsychiatric impairments, though they all emphasize the provision of ongoing individualized supports to meet a competitive employment outcome.

${ }^{16}$ For more details, see http://www.ssa.gov/disabilityresearch/promise.htm (accessed March 27, 2013). 
${ }^{17}$ For example, Burkhauser and Daly (2011) suggest using experience rating to encourage employer accommodations of disability. Autor and Duggan (2010) suggest using a mandatory short-term disability insurance program. Mann and Stapleton (2012) suggest testing an approach using a disability support administrator to address the fragmentations in the existing system. Finally, Liebman and Smalligan (2013) suggest testing several options and reforms to develop an evidence based approach to reforming disability policy. Stapleton and Wittenburg (2011) provides a review of several of the aforementioned proposals.

\section{Competing interests}

The IZA Journal of Labor Policy is committed to the IZA Guiding Principles of Research Integrity. The authors declare that they have observed these principles.

\section{Acknowledgments}

Funding for this article was made possible by the Research and Training Center on Employment Policy and Measurement Rehabilitation Research and Training Center, which is funded by the US Department of Education, National Institute for Disability and Rehabilitation Research (NIDRR), under cooperative agreement H133B100030. The contents do not necessarily represent the policy of the Department of Education, and you should not assume endorsement by the federal government (Edgar, 75.620 (b)). The authors are solely responsible for any errors or omissions.

The Responsible Editor is: David Neumark.

\section{Author details}

${ }^{1}$ Mathematica Policy Research, P.O. Box 2393, Princeton, NJ 08543-2393, USA. ${ }^{2}$ Mathematica Policy Research, 955 Massachusetts Ave., Suite 801, Cambridge, MA 02139, USA.

Received: 13 November 2012 Accepted: 8 April 2013

Published: 25 April 2013

\section{References}

Altshuler N, Prenovitz S, O'Day B, Livermore G (2011) Provider experiences under the revised ticket to work regulations. Mathematica Policy Research, Washington, DC

Autor D, Duggan M (2010) Supported work: a proposal for modernizing the U.S. Disability insurance system. The Center for American Progress; Hamilton Project, Washington, DC

Becker DR, Drake RE (2003) A working life for people with severe mental illness. Oxford University Press, Stony Brook, NY, USA

Benítez-Silva H, Buchinsky M, Rust J (2006) Induced entry effects of a \$1 for \$2 offset in SSDI benefits. Manuscript, SUNY-Stony Brook, UCLA, and University of Maryland, Stony Brook, NY

Benítez-Silva H, Disney R, Jiménez-Martín S (2010) Disability, capacity for work and the business cycle: an international perspective. Economic Policy 25(63):483-536

Berkowitz M (2003) The ticket to work program: the complicated evolution of a simple idea. In: Rupp K, Bell SH (eds) Paying for results in vocational rehabilitation: Will provider incentives work for ticket to work. Urban Institute, Washington, DC, pp 13-29

Bond GR (2004) Supported employment: evidence for an evidence-based practice. Psychiatric Rehabilitation J 27(4):345-359

Bond G, Wehman P, Wittenburg DC (2005) Evidence-based practices that promote employment of people with disabilities. Submitted to the national council on disability, social security study consensus validation conference. National Council on Disability, Washington, DC

Bond GR, Drake RE, Becker DR (2008) An update on randomized controlled trials of evidence-based supported employment. Psychiatric Rehabilitation J 31(4):280-290

Burkhauser RV, Daly MC (2011) The declining work and welfare of people with disabilities: what went wrong and a strategy for change. In: Burkhauser RV, Daly MC (eds) The declining work and welfare of people with disabilities. American Enterprise Institute, Washington, DC

Cook J, O'Day B (2006) Supported employment: a best practice for people with psychiatric disabilities. Policy Brief. Cornell University, Rehabilitation Research and Training Center on Employment Policy for Persons with Disabilities, Ithaca, NY

Cook JA, Leff HS, Blyler CR, Gold PB, Goldberg RW, Mueser KT, Toprac MG, McFarlane WR, Shafer MS, Blankertz LE (2005) Results of a multisite randomized trial of supported employment interventions for individuals with severe mental illness. Arch Gen Psychiatry 62(5):505

Cook JA, Blyler CR, Leff HS, McFarlane WR, Goldberg RW, Gold PB, Mueser KT, Shafer MS, Onken SJ, Donegan K (2008) The employment intervention demonstration program: major findings and policy implications. Psychiatric Rehabilitation J 31(4):291-295

Decker PT, Thornton CV (1995) Long-term effects of transitional employment services. Soc Sec Bull 58:71

Fraker T (2013) The youth transition demonstration: lifting employment barriers for youth with disabilities. Mathematica Policy Research, Washington, DC 
Fraker T, Baird P, Mamun A, Manno M, Martinez J, Reed D (2012) The Social Security Administration's youth transition demonstration projects: interim report on the career transition program. Mathematica Policy Research, Washington, DC

Frey WD, Drake RE, Bond GR, Miller AL, Goldman HH, Salkever DS (2011) Mental health treatment study: final report. Westat, Rockville, Maryland

Kerachsky S, Thornton C (1987) Findings from the STETS transitional employment demonstration. Except Child 53(6):515-21

Kornfeld R, Rupp K (2000) Net effects of the project NetWork return-to-work case management Experiement on participant earnings, benefit receipt, and other outcomes. Soc Sec Bull 63:12

Kregel J, Dean D (2002) Sheltered Vs. Supported employment: a direct comparison of long-term earnings outcomes for individuals with cognitive disabilities. In: Kregel J, Dean D, Wehman P (eds) Achievements and challenges in employment services for people with disabilities: the longitudinal impact of workplace supports. Virginia Commonwealth University, Richmond, Virginia

Liebman J, Smalligan J (2013) An evidence-based path to disability insurance. Working Paper. John F. Kennedy School of Government at Harvard University, Cambridge, MA

Livermore GA, Goodman N (2009) A review of recent evaluation efforts associated with programs and policies designed to promote the employment of adults with disabilities. Rehabilitation Research and Training Center on Employment Policy for Persons with Disabilities, Ithaca, NY

Luecking RG, Wittenburg DC (2009) Providing supports to youth with disabilities transitioning to adulthood: case descriptions from the youth transition demonstration. J Vocational Rehabil 30:241-251

Maestas N, Mullen K, Strand A (2011) Does disability insurance receipt discourage work? using examiner assignment to estimate causal effects of SSDI receipt. Rand, Santa Monica, CA

Mann DR, Stapleton DC (2012) A roadmap to a 21st-century disability policy. Issue brief report No. 12-01. Center for Studying Disability Policy, Washington, DC

Newcomb C, Payne S, Waid MD (2003) What do we know about disability beneficiaries' work and use of work incentives prior to ticket?: background information and baseline data. In: Rupp K, Bell SH (eds) Paying for results in vocational rehabilitation: will provider incentives work for ticket to work. Urban Institute, Washington, DC, pp 31-69

Peikes DN, Orzol SM, Moreno L, Paxton NA (2005) State partnership initiative: selection of comparison groups for the evaluation and selected impact estimates. Mathematica Policy Research, Princeton, NJ

Peikes DN, Moreno L, Orzol SM (2008) Propensity score matching. Am Stat 62(3):222-231

Rangarajan A, Wittenburg DC, Honeycutt TC, Brucker D (2008) Programmes to promote employment for people with disabilities: lessons from the united states. Mathematica Policy Research, Princeton, NJ

Ruiz-Quintanilla A, Weathers R, Melburg V, Campbell K, Madi N (2005) Participation in programs designed to improve employment outcomes for persons with psychiatric disabilities: evidence from the New York WORKS demonstration project. Soc Secur Bull 66(2):49-79

Rupp K, Bell SH (2003) Provider incentives and access in the ticket to work program: implications of simulations based on the project NetWork field experiment. In: Rupp K, Bell SH (eds) Paying for results in vocational rehabilitation: will provider incentives work for ticket to work. Urban Institute, Washington, DC

Social Security Administration (2012) Annual statistical supplemental to the social security bulletin. Social Security Administration, Baltimore, Maryland

Social Security Advisory Board (2012) Aspects of disability decision making: data and materials. Available at [http:// www.ssab.gov/Publications/Disability/GPO_Chartbook_FINAL_06122012.pdf]. Accessed on April 1, 2013

Stapleton D, Livermore G (2011) Costs, cuts, and consequences: charting a New course for working-Age people with disabilities. Mathematic Policy Research Center for Studying Disability Policy, no. 11-03, Washington, DC

Stapleton D, Livermore G, Thornton C, O'Day B, Weathers R, Harrison K, O'Neil S, Martin ES, Wittenburg D, Wright D (2008) Ticket to work at the crossroads: a solid foundation with an uncertain future. Mathematica Policy Research, Washington, DC

Stapleton DC, Burkhauser RV (2003) The decline in employment of people with disabilities: a policy puzzle. W.E. Upjohn Institute for Employment Research, Kalamazoo, Mich

Stapleton DC, O'Day BL, Livermore GA, Imparato AJ (2006) Dismantling the poverty trap: disability policy for the 21st century. Milbank Q 84(4):701-732

Stapleton DC, Wittenburg DC (2011) The SSDI trust fund: new solutions to an Old problem. Issue brief report No. 11-02. Center for Studying Disability Policy, Mathematica Policy Research, Washington, DC

Szymendera S (2011) Social security disability insurance demonstration projects. Congressional Research Service, Washington, DC

United States Government Accountability Office (2004) Social security disability improved processes for planning and conducting demonstrations may help SSA more effectively use its demonstration authority Washington, D.C. U.S. Government Accountability Office, Report GAO-05-19

United States Government Accountability Office (2005a) Federal disability assistance wide array of programs needs to be examined in light of 21st century challenges. report No. GAO-05-626. U.S. Government Accountability Office, Washington, DC

United States Government Accountability Office (2005b) Vocational rehabilitation: better measures and monitoring could improve the performance of the VR program. report No. GAO-05-865. US Government Accountability Office, Washington, DC

United States Government Accountability Office (2008) Federal disability programs more strategic coordination could help overcome challenges to needed transformation. Govt. Accountability Office. Report GAO-08-635, Washington, D.C.: U.S

Von Wachter T, Song J, Manchester J (2011) Trends in employment and earnings of allowed and rejected applicants to the social security disability insurance program. Am Econ Rev 101(7):3308-3329 
Weathers RR, Hemmeter J (2011) The impact of changing financial work incentives on the earnings of social security disability insurance (SSDI) beneficiaries. J Policy Anal Manag 30(4):708-728

Wehman P, Revell G (2005) Lessons learned from the provision and funding of employment services for the MR/DD population implications for assessing the adequacy of the SSA ticket to work. J Disabil Policy Stud 16(2):84-101

Whalen D, Gimm GW, Ireys HT, Gilman BH, Croake S (2011) Demonstration to maintain independence and employment (DMIE). Final report. submitted to the centers for Medicare \& Medicaid services. Mathematica Policy Research, Washington, DC

doi:10.1186/2193-9004-2-4

Cite this article as: Wittenburg et al:: The disability system and programs to promote employment for people with disabilities. IZA Journal of Labor Policy 2013 2:4.

Submit your manuscript to a SpringerOpen ${ }^{\circ}$ journal and benefit from:

- Convenient online submission

- Rigorous peer review

- Immediate publication on acceptance

- Open access: articles freely available online

- High visibility within the field

- Retaining the copyright to your article

Submit your next manuscript at $>$ springeropen.com 